\title{
Cross functional effect between language and culture in the understanding of the context in the educational process
}

\author{
Evgeny Nesmeyanov ${ }^{1}$, Yulia Petrova ${ }^{2 *}$ \\ ${ }^{1}$ Don State Technical University, Department of Philosophy and World Religion 344000 \\ Rostov-on-Don, Russian Federation \\ ${ }^{2}$ Rostov State University of Economics, Department of foreign languages for Economics \\ Professions, 344000 Rostov-on-Don, Russian Federation
}

\begin{abstract}
Teaching a communication language is not only grammatical patterns in which words are embedded, but it is also a function of the language. The function of the language - is the goal that must be achieved through written or spoken forms. Using the function of the language, you carry out the act of communication. The main goal in the communication process is to understand people, i.e. to understand the context. Culture is a central part to all types of the contexts. Understanding of the contexts implies that a person knows these cultural meanings related to time, place, person and circumstances. Many researchers define the main role of a teacher as a "driving force" in mastering cultural knowledge among students who study foreign languages during the education process.
\end{abstract}

\section{Introduction}

The topic of teaching and learning culture was the subject of many interests among teachers of foreign languages, which served as the basis for writing a large number of works devoted to the study of "the role of culture in the process of teaching a foreign language" over the past five decades. For an in-depth analysis of this issue, we should study the works of G. Moren, "Commitment to the teaching of foreign languages" (1983); F. Grittner, "A perspective on movements in foreign language education" (1990); D.H. Bragaw, "Priority Curriculum: The global imperative and its metalanguage" (1991). In recent years, various professional associations have made significant efforts to develop educational cultural standards (Standards, 1996; AATF, 1995). However, today there are several critical reviews of the literature. In some respects, this is not surprising, because teaching culture is not a serious prerogative of foreign language teachers. On the contrary, this issue is highly interdisciplinary in nature; contributions to this issue came from many disciplines, such as: psychology, linguistics, anthropology, intercultural communication, etc.

\footnotetext{
* Corresponding author: $\underline{\text { fimr.dstu@,mail.ru }}$
} 


\section{Results and discussion}

The methodology proposed by D.L. Lange [11; 139-177], C. Kramsch (1993) [1], N. Seelye (1994) [13], defines the study of culture, which is reflected in three fundamental learning processes: (1) student research and "their own culture"; (2) the discovery of the interaction between language and culture, and (3) the study of heuristics for analyzing and comparing cultures. Meta-awareness and cross-cultural comparison are the basis of cultural pedagogy, which provides an opportunity for interaction, where "representatives of the host culture can spread their own epistemology, their own way of worldview" to students $[16 ; 228]$. More than twenty years ago, G. Robinson-Stuart (1978) noted in his studies that it is the means that determine the goals; if the goal is to understand people, then this implies an "emotional personal response" to real people [6;435].

Thus, the main goal in the communication process is to understand people, i.e. understanding of the context. In his research, M. Byram (1988) argues that language does not have any function independent from the context in which it is used, thus language always refers to a cultural context. This cultural context defines the language patterns that are used when connecting individuals, in certain circumstances and at a specific time and place. This combination of elements always has cultural significance, which affects the use of language [12; 15-31]. S. B. Heath (1986) argues that most human interactions are based not so much on people having common deep knowledge of each other, but on their understanding of the context in which communication takes place. Understanding of the context implies that a person knows these cultural meanings related to time, place, person and circumstances. This understanding, in turn, prescribes linguistic behavior which is appropriate to these circumstances. In fact, there is no need to know a person in order to communicate with him/her, the only thing that is important - is an understanding of the context. The central and recurring theme in the discussion of the context is the idea of semantic structures related to time, place, person and circumstances [17].

W. B. Gudykunst \& Y. Y Kim, (1992) argue that there are two types of contexts that play an important role in intercultural communication. The external context refers to various places where people interact [19]. For example, two people treat each other in a more formal setting in the office than if they met and talked on the street. Culture regards the workplace as a more formal and professional setting, rather than a social zone. The external context carries social significance on a larger scale, that is, the ways in which a particular cultural group constructs various parameters of human interaction and communication. The internal context, on the other hand, refers to the cultural meanings in which people enter into mutual communication. The internal context creates the conditions for understanding or misunderstanding between people of different cultures. So in the research of T. Hall (1976), there are many cultural variations that affect the way people perceive situations and each other. For example, the "communication range" depends on how far the communicants are from each other during the conversation; how much time are they willing to spend on communicating with each other, etc. [3].

In order to illustrate these concepts, we can consider the language class as a parameter and learn how to use the language. The basis of external factors is the social attitude to the education process, in general, and which models represent the corresponding behavior in the work of the teacher and students in the educational process. Another external factor is the way the second language is taught and the attitude towards the knowledge of the second language in the society. Internal contextual factors include phenomena such as motives, interests, and the understanding of students and teachers as the main carriers of behavioral qualities reflected in the educational process, in general, as well as in the use of a second language, in particular. 
Over the past fifty years, important changes had occurred in the way of language teachers view the context. The main issue was the interaction of language and culture in the learning process. In the 1960s, many researchers and teachers of foreign languages believed that understanding the context was crucial for learning the language, which served as the basis for creating various study programs abroad and modeling culture in the educational process. In the 1970s, there was a shift towards a cognitive-oriented model in the field of education, which led to a significant decline in attention to the role of the context and the experience in the learning process $[18 ; 469-493]$. From the 1980 s to the present, much attention had been focused on the contexts of teachers of foreign languages, which was an attempt to "contextualize" (that is, create an opportunity to study the meaning in the learning environment) [15]; [18]. Study programs abroad, student exchange during the educational process, are becoming increasingly popular, both in Russia and abroad, with the aim of creating a real cultural context and complete plunge into the language environment.

Since the 1990s, a communicative approach has been widely applied. Since it describes a number of very general principles based on the concept of communicative competence as the goal of teaching in the second foreign language, and the communicative program and methodologies as the means of achieving this goal, thus, communicative language teaching continues its development. The current communicative theory and practice of language teaching are based on a number of different educational paradigms and traditions. Various sources lead to a variety of interpretations, which allows us to conclude that there is no single or agreed set of practices that characterize the current teaching of communicative language skills. Most likely, teaching in order to teach students communicative language skills today refers to a set of generally agreed principles that can be applied in different ways, depending on the learning context, the age and level of students, as well as their learning goals, etc. [8].

Many researchers define the main role of a teacher as a "driving force" in mastering cultural knowledge among students of language education. G. H. Hughes (1986), notes that a teacher must be a philosopher, geographer, historian, philologist, and literary critic [5; 162-169]. According to H. B. Altman (1981), the teacher fulfills the function of "a qualified developer of communicative competence in the classroom", "dialectologist", "explains the value component, and also carries the function of a "communicative analyst" [7; 11-13]. The role of the teacher is the ability to show the qualities of an educational sociologist, according to R. C. Kleinsasser [14; 373-83]. L. Kane (1991), in his work "The Taxonomy of Cultural Research Goals" [16;191], it is noted that the teacher should be an anthropologist and ethnographer, an intercultural teacher, and, of course, a comparative sociolinguist who defines the inputs and outputs of cultural-linguistic change.

Almost all children at an early age learn the language without special effort. In many parts of the world, children grow up with the knowledge of two or more languages. If children move to another country, then they study in this country and learn another language. Children learn the language subconsciously. Can students be taught a second language at a subconscious level? Some theorists, mainly an American representative of applied linguistics S. Krashen, in the 1980s suggested distinguishing two words - mastery and study. Mastering the language occurs at a subconscious level and without anxiety, and the learning process - at a conscious level, studying and practicing certain aspects of the language $[9 ; 48]$. Krashen suggested that teachers focus on the concept of mastering the language, rather than learning it, and so that the role of a language teacher would be reduced to the correct disclosure of the language, namely, by conceptual means (i.e., a language that students understand more or less).

Today's practice of teaching language is a direct result of numerous disputes and discussions not only on how to speak a language or how to learn it. In the 90s of the last century, there was a discussion of the Lexical Approach [9; 49] to compiling curricula 
based on the study of lexical large phrases - blocks (language chunks). It can be idioms or collocations. Thus, we can consider the study of English using the example of the scholarly linguist M. Halliday, who pointed to the tendency to say "strong tea" instead of "powerful tea", although they are equal in meaning. Native speakers say "heavy" about "rain," not "strong." The English say "make yourself at home." The linguist, N. Schmidt, suggests using existing pre-defined phrases and not looking for ways to express thoughts every time we want to say something in English. In the 70s of the last century, methods such as the Silent Way (when teachers spoke English and the responsibility for understanding rested with students), or Community Language Learning - learning the community language (when a bilingual teacher helps students to translate what they want) were promoted to say in their native language, the language they learn), the grammar-translation method $[9 ; 49-$ $50]$, which got its name in Germany in the $1780 \mathrm{~s}$, presented the idea of a brief interpretation of grammar rules and a dictionary, and then exercises for translation were suggested in which they needed to use these rules and words. Now this method is not practiced in this form. But most learners of the language, as it were, translate a lot about a foreign language in their heads at different stages, comparing the elements of a foreign language with the elements of our own native language, where cultural concepts are layered on the language. However, the full concentration on this method does not allow students to get the initial information in a natural language that will help them learn the language (since they are always looking for an equivalent in their native language, in their native culture), and this deprives them of the opportunity to activate their own language knowledge. If they always translate into their own language, then they will never be able to use a foreign language for communication. The danger of this method is, if briefly, that it gives a concept of a language, but does not teach people to communicate in it.

Any type of speech has its own linguistic features, regardless of the country of the language being studied. The existence of numerous techniques does not exclude the fact that knowledge of the culture of the language being studied is closely interrelated and cannot be considered separately. To date, in higher educational institutions, the content of the taught academic disciplines, such as foreign languages and the study of the culture of a given country and society, did not provide for the study of individual aspects of objects, but they were not interpreted as a comprehensive study. As a result of this, the acquired knowledge is formed in a fragmentary form, which in many cases does not make it possible to find an independent creative solution to the question of the interaction of language and culture in understanding the context in the educational process.

Russian researchers like: M. N. Skatkin, V. V. Kraevsky, I. Ya. Lerner in the theory of didactic structures argued that the culture of human society consists of the following four elements that should be expressed in the content of education:

a) accumulated knowledge about nature, society, methods of thinking, production and activity;

b) experience in the implementation of certain methods of activity;

c) the experience of finding creative solutions to new problems that arise in the society;

d) the normative attitude to the world and the normative attitude of people towards each other, that is, moral-volitional upbringing and so on. Each of these elements has specific features, none of them can replace the other and perform the functions of the other $[4 ; 46]$.

These initial elements can exist separately on their own, but subsequent elements cannot exist without the previous ones. For example: it can know, but it cannot execute; may know, may also perform some standard tasks, but not ready for creative activity; may know, performs tasks, and is also engaged in creativity, but the attitude to this activity is different. It follows from this that the above should be reflected in the content of education.

\section{Conclusions}


Thus, in the modern world, the fact that culture occupies a central place in all types of contexts indicated by the authors and researchers in our article is becoming more and more obvious. This is not the context itself, which changes the use of language or the model of behavior between actors who have entered into the communication process, but the meaning associated with this context, and this meaning is determined by culture. Therefore, it is extremely important for students studying a foreign language to show greater interest in the study of culture. Students should know and understand how to "read" the context. This suggests that language learning should provide an opportunity for students to be exposed to, or better yet, "immerse themselves" in culture, in order to acquire skills in determining the cultural meanings of time, place, person and circumstances.

\section{References}

1. C. Kramsch, Context and culture in language teaching (1993)

2. D.L. Lange, R.M. Paige, Culture as the Core: Perspectives on Culture in Second Language Learning (2003)

3. E.T. Hall, Beyond culture (1976)

4. E.N. Puzankova, A.I. Uman, M.A. Fedorova, M.N. Skatkin, The prospects for the development of domestic pedagogy (2010)

5. G.H. Hughes, An argument for culture analysis in the second language classroom (1986)

6. G. Robinson-Stuart, H. Nocon, MLG, 80(4), 435-436 (1996)

7. H.B. Altman, What is second language teaching (1981)

8. J.C. Richards, Communicative Language Teaching Today (2006)

9. J. Harmer, How to teach English (2007)

10. L. Kane, The acquisition of cultural competence: An ethnographic framework for cultural studies curricula (1991)

11. L.M. Crawford-Lange, D. Lange, Doing the unthinkable in the second-language classroom: A process for integration of language and culture (1984)

12. M. Byram, LCC, 1(1), 15-31 (1988)

13. N. Seelye, Teaching culture: Strategies for intercultural communication (1994)

14. R.C. Kleinsasser, TTE, 9 (4), 373-383 (1993)

15. R. H. Moos, E. Trickett, Classroom environment scale manual (1987)

16. R. Jurasek, Using ethnography to bridge the gap between study abroad and the oncampus language and culture curriculum (1995)

17. S.B. Heath, Beyond language: Social and cultural factors in schooling language minority students (1986)

18. V. Edwards, S. Rehorick, CLMR, 46 (3), 469-493 (1990)

19. W. B Gudykunst \& Y. Y. Kim, Readings on communicating with strangers: An approach to intercultural communication (1992) 